\title{
The Development of High Efficiency Integrally Geared Driven Multistage Centrifugal Compressor
}

\author{
Leilei Han*, Fubao Li, Ning Li, Haiyang Zhou, Lihui Jiang, Zongyang Wang
}

Huayi Turbomachinery (Shandong) CO., LTD, Weifang City, China

Email address:

hl19029@163.com (Leilei Han)

${ }^{*}$ Corresponding author

\section{To cite this article:}

Leilei Han, Fubao Li, Ning Li, Haiyang Zhou, Lihui Jiang, Zongyang Wang. The Development of High Efficiency Integrally Geared Driven Multistage Centrifugal Compressor. International Journal of Fluid Mechanics \& Thermal Sciences. Special Issue: Fluid Mechanics \& Thermal Sciences in Turbomachines. Vol. 6, No. 2, 2020, pp. 53-60. doi: 10.11648/j.ijfmts.20200602.12

Received: April 23, 2020; Accepted: June 2, 2020; Published: June 28, 2020

\begin{abstract}
Integrally geared multistage centrifugal compressors have been widely used in many industries. The design of the new compressor is very complicated and needs a reliable design process. This paper discussed the development of a high efficiency integrally geared driven centrifugal compressor for industrial applications. An inhouse program was used to design the centrifugal compressor through aerodynamic and structural optimization. CFD (Computational Fluid Dynamics) is a very important tool for centrifugal compressor design. CFD can help compressor design and perform three-dimensional optimization to further optimize the compressor. The compressor stage matching is also impact the overall compressor performance. The good stage match is very important to make the design success. The Finite Element Analysis (FEA) was used to verify the structure integrity. The CFD and FEA (Finite Element Analysis) analysis are performed to obtain a final compressor performance and to make sure to have a robust operation. The centrifugal compressor has the characteristics of high efficiency, no resonance, and low noise. The designed compressor prototype was built and performance tests were conducted. The performance test results demonstrated that the analytical are fairly agreed with experimental results. The development process and tools are successfully used in the compressor design. The design process can be used for future compressor development.
\end{abstract}

Keywords: Centrifugal Compressor, Compressor Design, CFD, FEA

\section{Introduction}

Centrifugal compressors, as fluid machinery, play a vital role in promoting economic development. They belong to indispensable industrial equipment in the fields of air separation, chemical engineering, electronics, and energy. The integral gear compressor has a compact structure and low cost, and can be divided into a single-stage or a multi-stage compressors [1-24]. Due to the high rotating speed of the gear pinion, the compressor impeller has a high blade tip speed. Most of the impellers are semi-open impellers. This paper designs a new high efficiency multi-stage centrifugal compressor with a short time frame. After the compressor was designed, the numerical calculations and experimental studies were performed.

The new compressor is a three-stage compressor. The total pressure ratio of the compressor is 9.7 and the inlet flow rate is about $2.0 \mathrm{~kg} / \mathrm{s}$ at standard inlet conditions $\left(0^{\circ} \mathrm{C}\right.$ temperature and 1 bara pressure and $60 \% \mathrm{RH}$ ). The design goals of this unit need to have the characteristics of high efficiency, wide stable operating range, no resonance, and low noise. In this paper, computer fluid mechanics method is used for final design compressor numerical analysis. The Finite Element Analysis (FEA) was used to verify the structure integrity. The design tasks using newly developed tool [22] can be efficiently completed and optimized, and then the performance of the whole machine is tested experimentally and compared with numerical simulation results.

The compressor design normally starts with design considerations $[1,3]$. The design considerations provide the overall selection and sizing of the compressor. The compressor preliminary parameter selections and compressor package designs are the beginning of the design. CFD (Computational Fluid Dynamics) is a very important tool for centrifugal compressor design. CFD can help compressor design and perform three-dimensional optimization to further 
optimize the compressor. The compressor stage matching also impacts the overall compressor performance. A good stage match is very important to make the design successful [4].

The integrally geared centrifugal compressor is an important industrial equipment in the fields of air separation, chemical, electronic, energy and other industries, which plays an important role in the development of economy as fluid machinery. The integrally geared centrifugal compressor has compact structure, good performance, low noise, and low cost. It can be divided into single stage compression or multi-stage compressors. This paper mainly discusses the first stage compressor design. The design method of the other stages is the same. The CFD and FEA were performed for the final design. The CFD results were demonstrated that the design is successful and FEA demonstrated that the design is reliable.

\section{Compressor Design}

Centrifugal compressors typically consist of an impeller, diffuser, and volute or collector. A good centrifugal compressor design system needs to include all compressor component designs and performance estimations. The compressor direct design process typically requires more time in the aerodynamic and structure interactions, but it can generate more accurate designs to meet the manufacturing requirements. Direct design can also easily reach the structured and manufacturing targets. In the design iteration, all designs are evaluated by aerodynamic and structural integrity as well as manufacturing capability. The final design is the results of design optimization for both aerodynamics and reliability. The current used design system is a direct design base system [22].

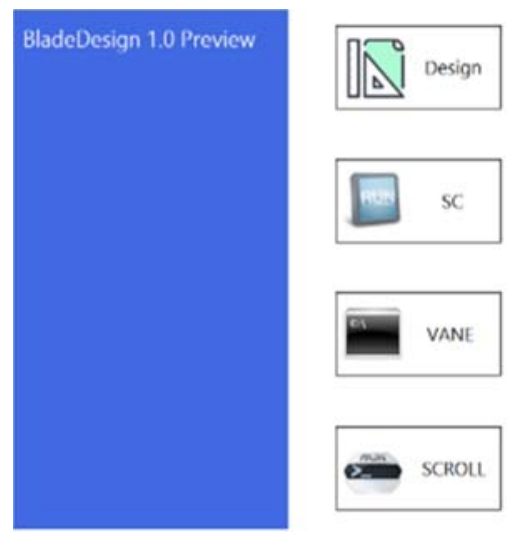

Figure 1. The design system.

The detail geometry design consists of four parts: impeller design (Design), impeller scale (SC), vane and scroll design as shown in Figure 1 [22]. The design system has a good user interface with many input and output functions in the design system to transfer data to CAD and five-axial machines. The design system is very flexible and easy to use. The impeller can be designed based on the one-dimensional optimization results or scaled from existing impellers based on the design targets. The compressor diffuser and scroll can also be created based on the designers' parameter inputs or system default design based on the impeller design and design targets. In this design, after one-dimensional parameter studies, the scaling method was used from the best design from the database. The scaled the compressor stage was further optimized in a three-dimensional way. The final optimized design obtained. The three stages of the compressor were designed in a similar way. The main parameters of all stages are shown in Table 1.

Table 1. Main parameters for all stages.

\begin{tabular}{llll}
\hline Parameters & stage-1 & stage-2 & stage-3 \\
\hline Inlet total pressure (Kpa) & 100 & 276 & 491 \\
Inlet total temperature $(\mathrm{k})$ & 308.15 & 313.15 & 313.15 \\
RPM (r/min) & 34708 & 34708 & 52063 \\
Massflow $(\mathrm{kg} / \mathrm{s})$ & 1.97 & 1.96 & 1.95 \\
Number of blade & $8 \times 8$ & $8 \times 8$ & $7 \times 7$ \\
Tip clearance $(\mathrm{mm})$ & 0.25 & 0.22 & 0.22 \\
\hline
\end{tabular}

The current designed three-stage gear centrifugal compressor is driven by a motor through a diaphragm coupling. The prototype of the final design is shown in Figure 2. It can be seen that the large gear drives two driven pinion shafts arranged in parallel on both sides. The first and second stages are coaxial to form a low speed rotor. The volute and the flow channel are located on the gear box body. In addition, the unit has three interstage coolers and the gearbox is integrally casted. Gas enters the impeller through the inlet guide vane device. The impeller is driven by the gear to rotate at high speed. The gas is compressed into the diffuser, which expands and reduces the speed. The volute introduces the high-temperature compressed gas into the cooler through the flow channel The cooled compressed gas flows into the second stage and the third stage through the pipeline, and is sequentially compressed to finally obtain the set pressure and flow rate. The structure reliability is very critical for the compressor operation. The FEA analyses were performed for gearbox, volute, based plate and impeller. The calculations demonstrated that the compressor unit meets the reliability goal. The impeller life is one of the keys for compressor operations. The stress and modal analysis results are shown in Figures 3 and 4. Figure 3 showed that the maximum von-Mises stress is 589.79MPa which is about much lower that material's ultimate tensile stress of $1103 \mathrm{MPa}$ [25]. This level of stress can make sure the impeller can run for a long time. Figure 4 showed that the impeller did not have any vibration issue because impeller and diffuser excitations dont near any critical speed.

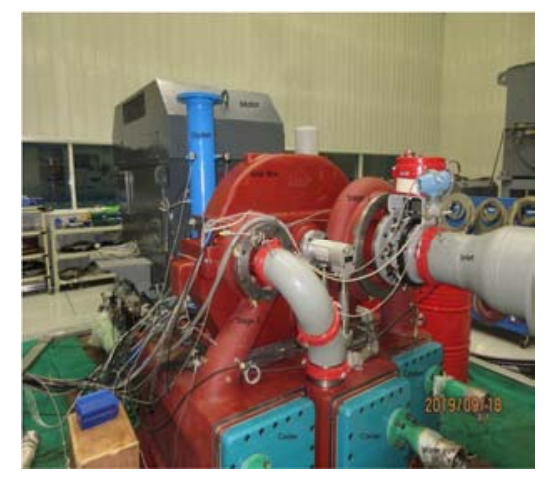

Figure 2. Test prototype. 


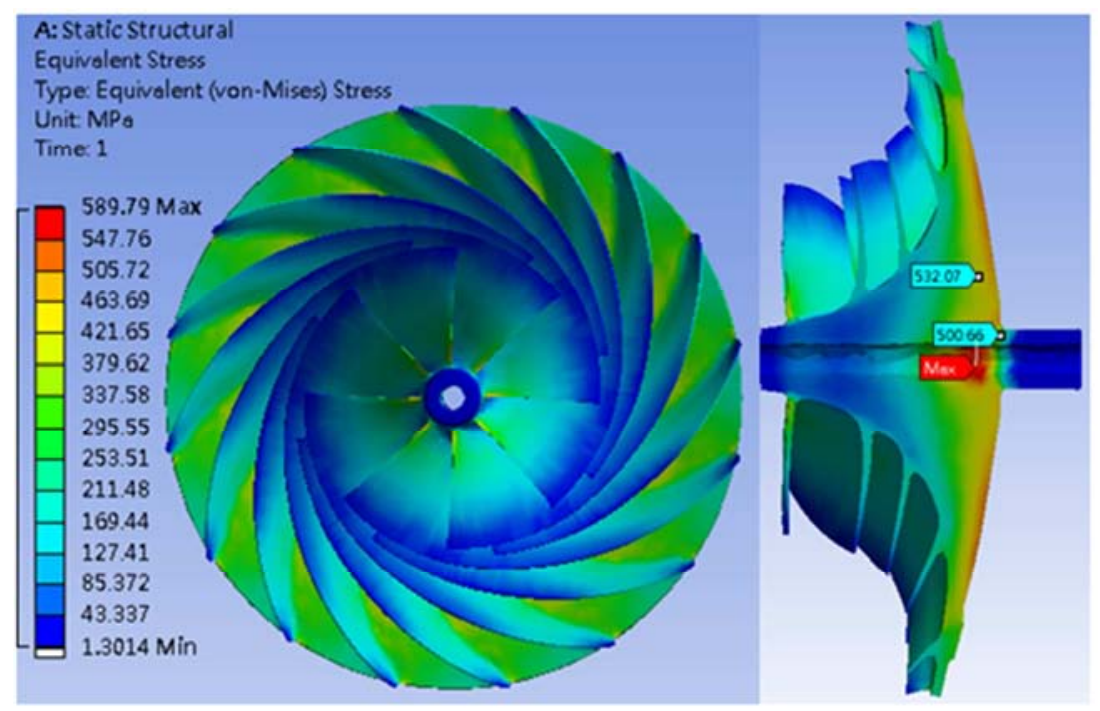

Figure 3. Impeller stress FEA results.

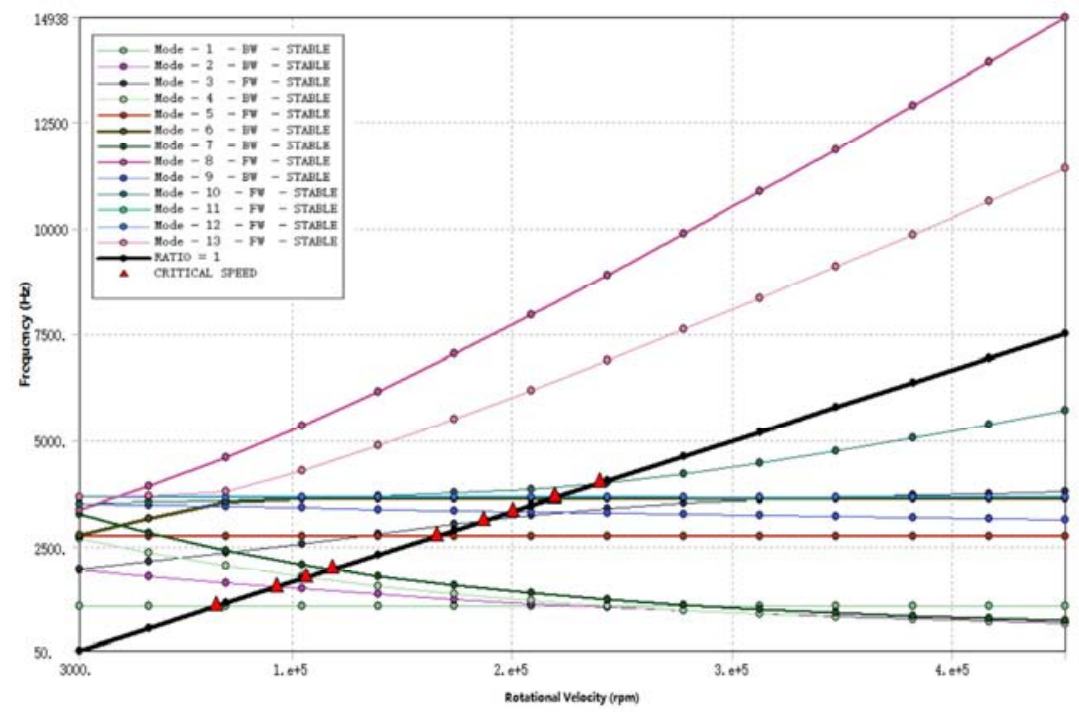

Figure 4. Impeller modal analysis results.

\section{Numerical Simulation}

Numerical simulation is mainly divided into three processes: pre-processing process, solving process, and post-processing process. The pre-processing needs to solve the state of the problem i.e. defines the problem and creates the grid and boundary conditions. In this study, air is assumed as an ideal. A turbulent steady state solver is selected. The KE model is selected. The convergence needs to be below 1.0x10-5 for residuals of all parameters. Post-processing is to report the numerical calculation results, such as velocity vector diagrams, pressure temperature cloud diagrams, etc. Numerical simulation has taken the first stage as an example and other stage calculations are similar.

Grids are very critical for numerical simulations. After grid independent studies, the number of impeller grids use 612885 , diffuser grids is 564720 , volute is 451658 as shown in Figure 5. CFD calculations are performed for all the stages. The stage-1 results are presented in detail here. The CFD calculation used pressure ratio as the boundary conditions and mass flow rate is the calculation results. The CFD calculations showed that when using a pressure ratio of 2.9 at the design point as boundary condition, the flow rate is $2.1 \mathrm{~kg} / \mathrm{s}$. The design target mass flow rate is $2.0 \mathrm{~kg} / \mathrm{s}$. The CFD calculated adiabatic efficiency is $84.86 \%$ which is higher than design specification the adiabatic efficiency of $82.5 \%$.

Figure 6 is the CFD streamline. It can be seen that there is no flow circulation and flow separation in the impeller and diffuser. It can be seen that the air enters the enter impeller in rotational axial direction and exits in radial direction of the impeller. The air enters the impeller, the speed increases and air energy increases due to impeller work; and then air speed decreases when it enters the diffuser. Figure 7 shows the blade loading distributions i.e the impeller blade surface pressure pressure distribution, at near hub (10\% height), mid-height (50\% height) and tip ( $90 \%$ height). It can be seen that there is a small positive 
incidence near the hub and a small negative incidence near shroud. The small positive incidence near the hub benefits the compressor efficiency and small negative is good for surge margin.

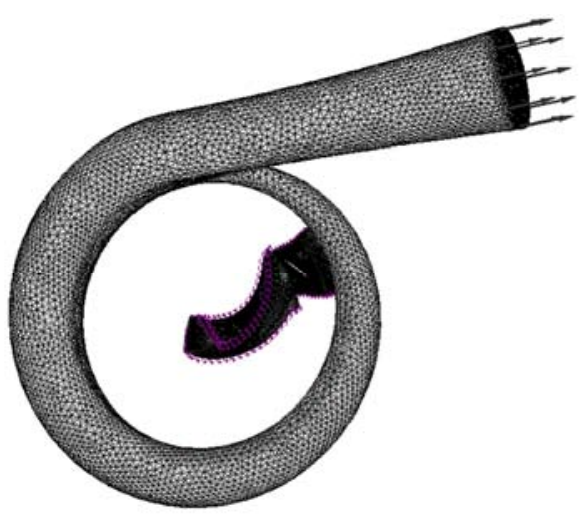

Figure 5. Calculation grid.

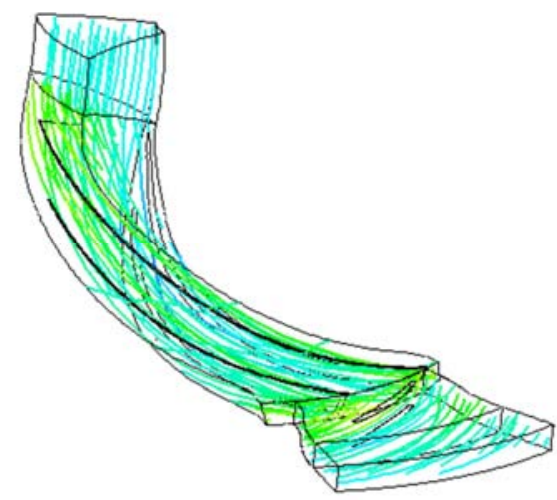

Figure 6. Streamline.

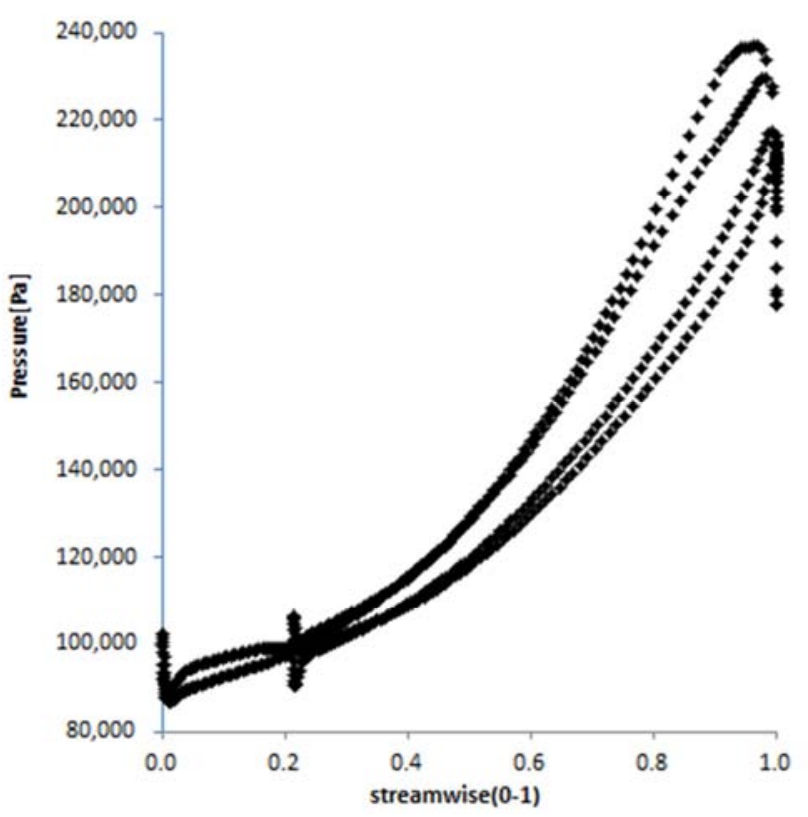

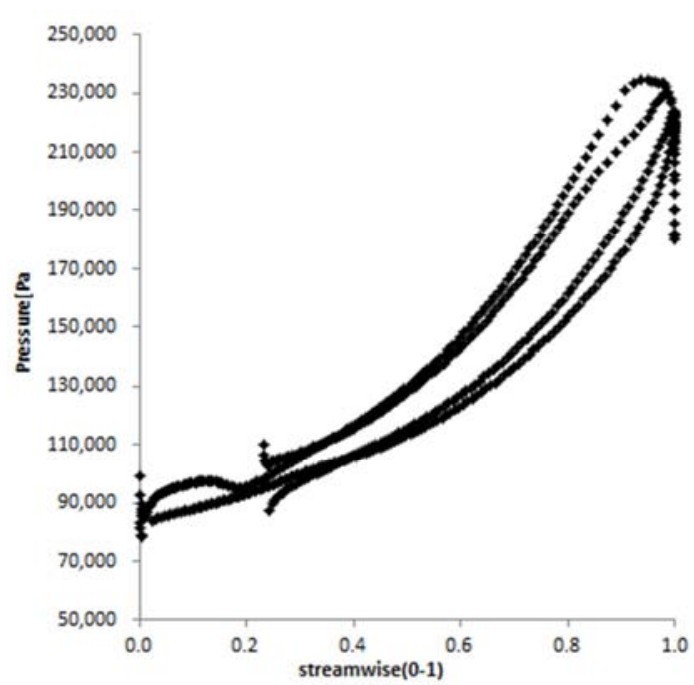

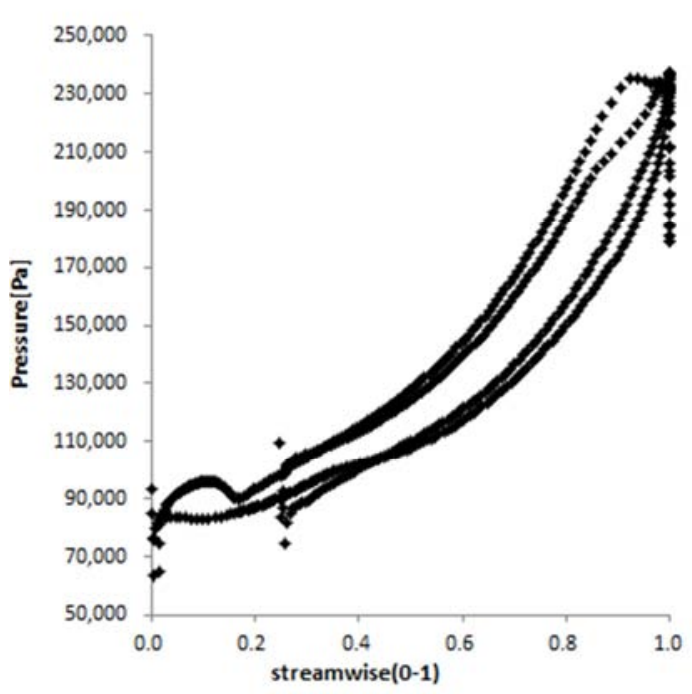

Figure 7. Impeller blade static pressure distribution.

Figure 8 is the static pressure, entropy and velocity vectors near the hub (10\% height) of the impeller. The static pressure contour shows that the static pressure increases inside of the impeller blade. At the inlet of the main blade, static pressure increases faster at the pressure side of the main blade. This is because the pressure side air velocity reduces and pressure increases. However, when air passes through the splitter, the pressure difference of two sides of the blade reduces. The uniform pressure at the exit of the impeller reduces the secondary flow moves from high pressure side to low pressure side. This design character benefits the compressor performance. The entropy contour shows that high losses exist around the two sides of the middle of the main blade. The velocity vector indicated that the low speeds exist in these areas. Figure 9 is the static pressure, entropy and velocity vectors at the mid-blade span (50\% height) of the impeller. The static pressure contour shows that the static pressure increases inside of the impeller blade is uniform. There is a small incidence in the splitter blade. This is due to the splitter and main blade use the same design. For further optimization, the splitter can use different designs. However, the main blade 
and splitter using different designs will increase the manufacturing cost. In this design, due to the cost limitation. Figure 10. is the static pressure, entropy and velocity vectors near shroud ( $90 \%$ height) of the impeller. The static pressure contour shows that the static pressure increases inside of the impeller blade is relatively uniform. The entropy distribution indicated that the flow losses in the tip is highest compared with hub and mid-span. This is because the tip clearance increases the flow leakage and increases the secondary flow losses. The velocity vector plots indicated that there is no separation. This indicated that the current design is a reasonably good design. Figure 11 is the meridional flow characteristic plots. Static pressure distribution indicates that the impeller exit static pressure in perpendicular to flow direction is very uniform. This can reduce the secondary flow losses. The entropy distribution indicates that the highest losses in the impeller is near the shroud of the impeller exit.
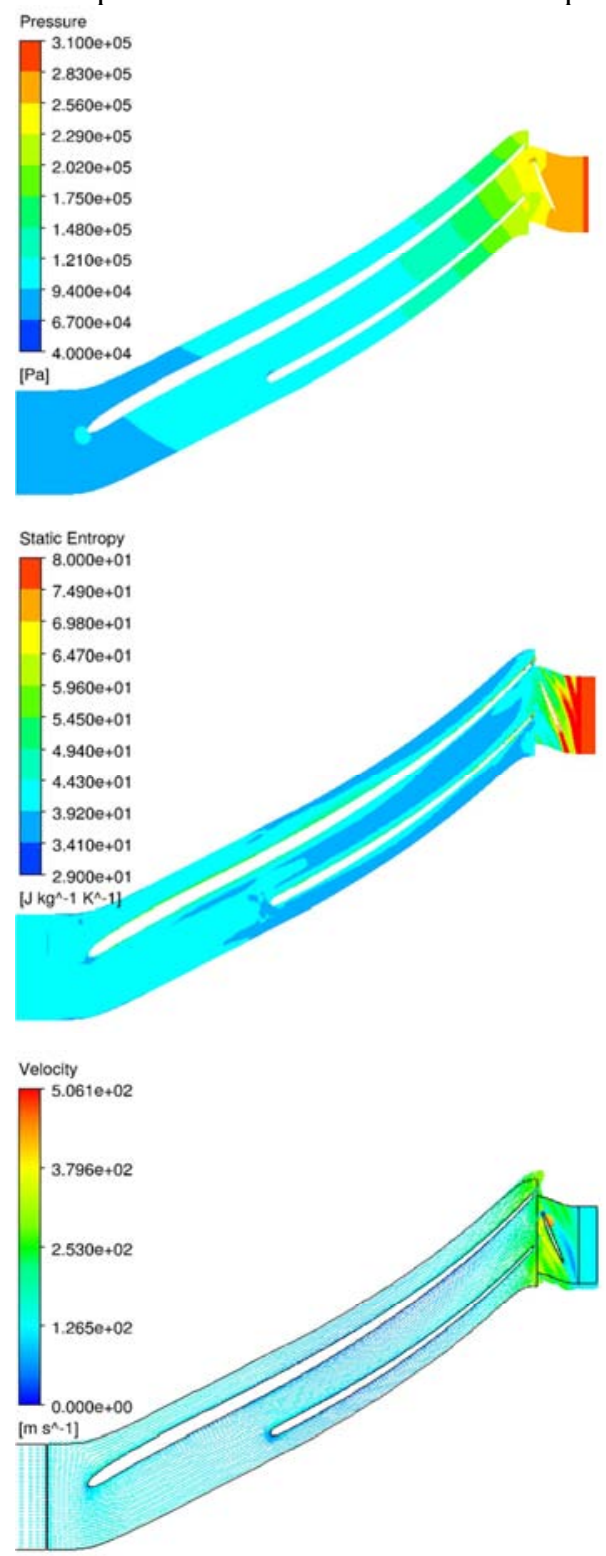

Figure $8.10 \%$ blade height position pressure, entropy, velocity distribution.
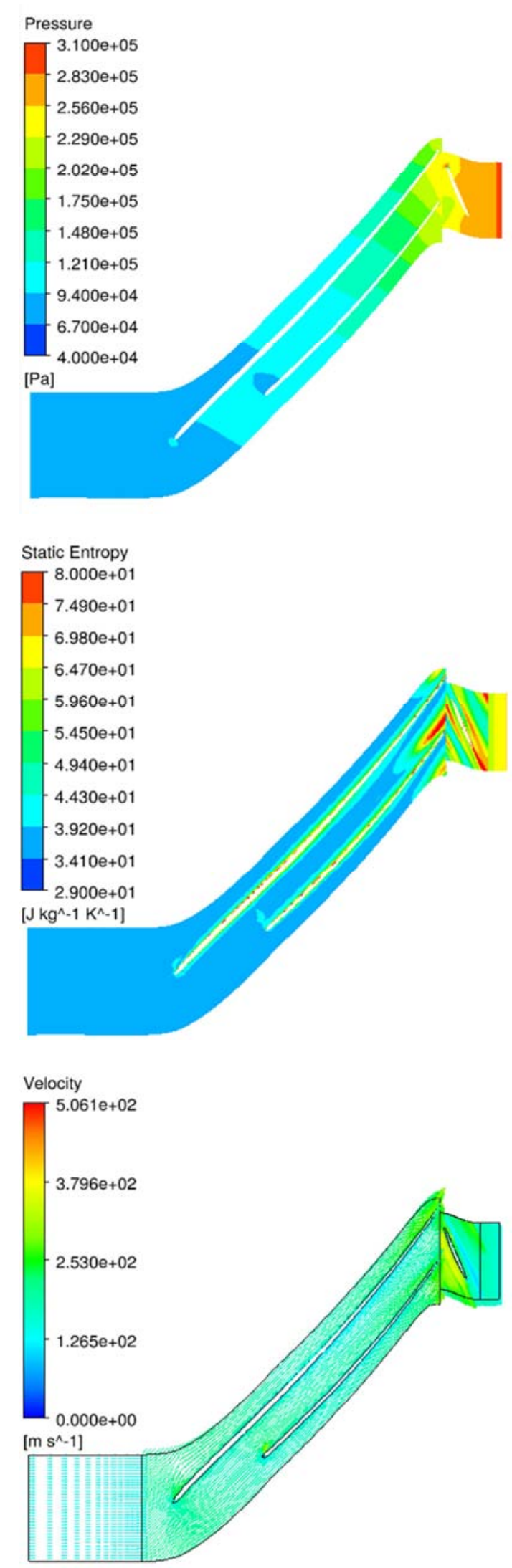

Figure 9. 50\% blade height position pressure, entropy, velocity distribution. 

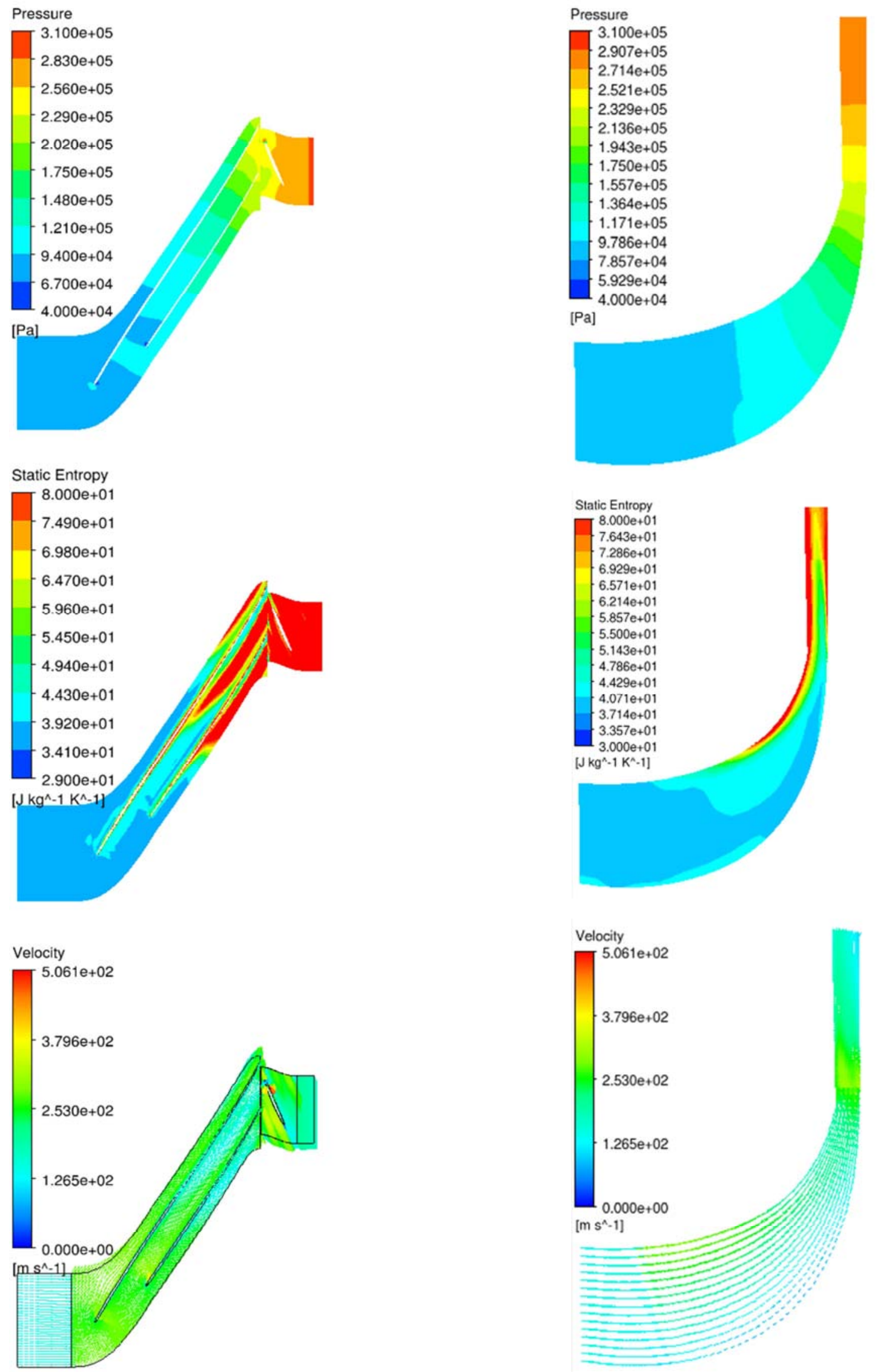

Figure 10. 50\% blade height position pressure, entropy, velocity distribution.

Figure 11. Distribution of pressure, entropy, and velocity in the meridian. 
The compressor prototype was built for a performance and reliability test. The test was performed in the development laboratory. The reliability overspeed test was performed first for the test unit as shown in Figure 2. The motor was drived through a frequency drive which can change the motor speed in order to do over speed test. After the mechanical run, the performance test was performed. In order to test the compressor over all performance and the performance of each stage, two pressure transducers and two thermocouples were installed at the inlet and outlet of the stage as shown in Figure 2. The measurement results of the pressure and temperature values are the average of the two measurements. The flow measurement was measured through an orifice plate. The measurement uncertainty for compressor efficiency is about $0.4 \%$ ad flow is about $2 \%$. Figure 12 is the measurement and computational result comparison. The computational results summarize the two pressure ratios: one is the pressure ratio from inlet to impeller exit and another is the stage pressure ratio. It can be seen that the measurement data is in a fairly good agreement with computational results. The curve shape of the impeller pressure ratio with flow rate is similar to the stage pressure ratio. It can be seen that the impeller performance dominates the stage pressure performance. Figure 13 is the relationship of the adiabatic efficiency with flow. It can be seen that the measured efficiency is in a good agreement with calculation results. The curve shape of the impeller adiabatic efficiency is very similar to the curve of the stage efficiency. However, the impeller peak efficiency point is more close to the high flow rate. This is because for the high flow rate, the scroll losses increase faster when compressor flow rates increase. The flow change from volumetric flow of peak efficiency to that of location of $10 \%$ lower efficiency is over $30 \%$. This indicated that the compressor has a good surge margin. The measurements indicated that the calculations represent the measurement data. The design systems in this design is success and can be used for future developments.

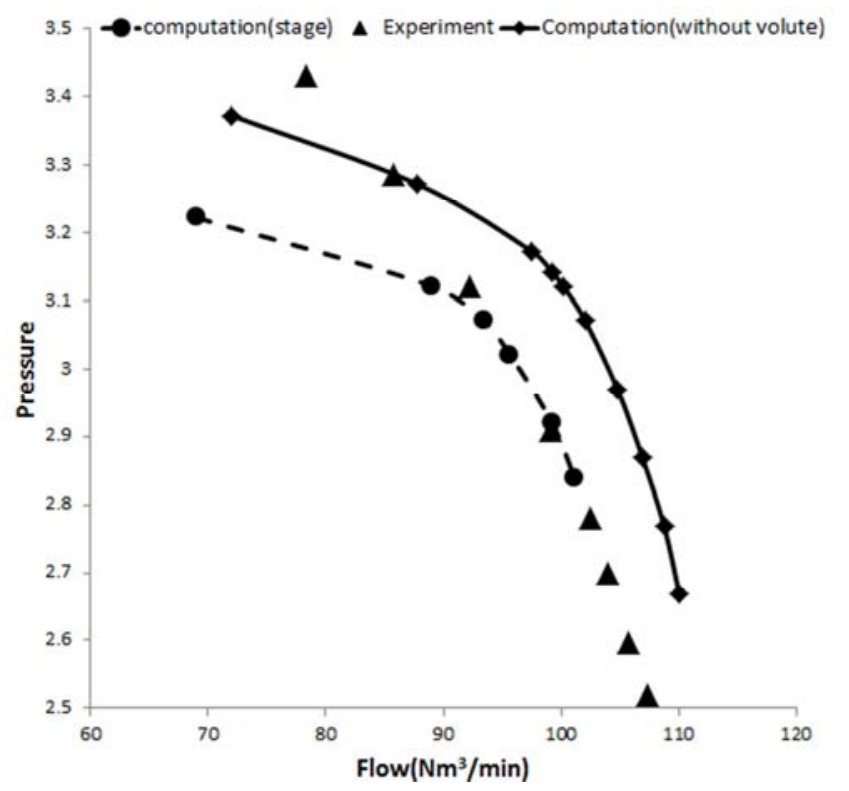

Figure 12. Flow pressure characteristics.

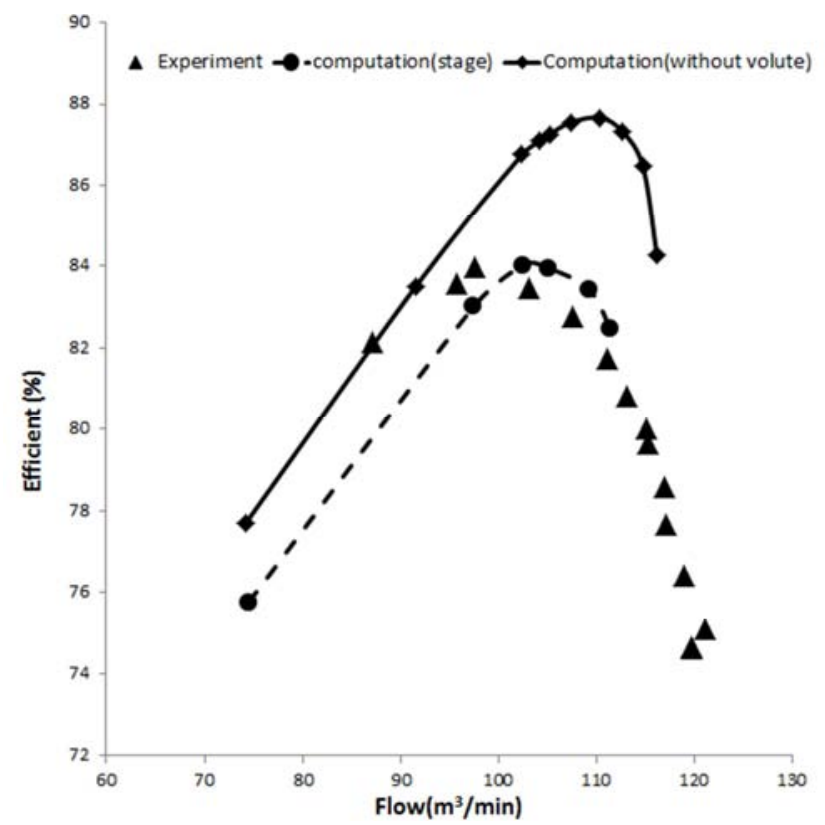

Figure 13. Efficiency characteristics.

\section{Conclusions}

This paper reported a new compressor development by using a recently developed design process. The compressor design process provides a good user interface and allows designers to design a centrifugal compressor stage to meet the design requirements in a short time. The design process integrates the aerodynamics and structure optimization together and can ensure the designs meeting both performance and structure requirements. The prototype was built and a performance test was performed to verify the design methods and numerical simulations can be good tools for centrifugal compressor development.

The first stage design and test results are reported in detail here to demonstrate the design process is a good design tool and can be used for future compressor development. This unit test showed that the compressor unit met the design requirements. The flow, pressure ratio and performance met the design targets. The design using low solidity vaned diffuser and with small negative shroud incidence provide the compressor a good surge margin. This strategy can be used for future development.

\section{References}

[1] C. Xu, Design Experience and considerations for centrifugal compressor development, Journal of aerospace engineering, 221 (2007) 273-287.

[2] C. $\mathrm{Xu}, \mathrm{M}$. Muller, The design and development of a centrifugal compressor volute, International journal of rotating machinery 2006.

[3] C. Xu, R. S. Amano, Empirical Design Considerations for Industrial Centrifugal Compressors, International Journal of Rotating Machinery, 2012 (2012) 1-16. 
[4] C. Xu, R. S., Development of a Low Flow Coefficient Single Stage Centrifugal Compressor, International Journal for Computational Methods in Engineering Science and Mechanics, 10 (2009) 282-289.

[5] C. Xu, R. S. Amano, 2009, The Development of a Centrifugal Compressor Impeller, International Journal for Computational Methods in Engineering Science and Mechanics, 10 (2009) 290-301.

[6] C. Xu, R. S. Amano, On the Development of Turbomachine Blade Aerodynamic Design System, International Journal for Computational Methods in Engineering Science and Mechanics, 10 (2009) 186-196.

[7] C. Xu, R. S. Amano, Study of the flow in centrifugal compressor, int. J. of Fluid Machinery and System, 3 (2010) 260-270.

[8] Xu, C., Impeller for a centrifugal compressor, US Patent. US7563074 B2 https://www.google.com/patents/US7563074.

(2005).

[9] W. F. Castle, Air separation and liquefaction: Recent developments and prospects for the beginning of the new millennium," International Journal of Refrigeration. 25 (2002) $158-172$.

[10] C. Xu, R. S. Amano, Effects of Asymmetric Radial Clearance on Performance of a Centrifugal Compressor, ASME Journal Energy Resource Technology, 140 (2017) 052003-0520016, doi: $10.1115 / 1.4038387$.

[11] C. Xu, R. S. Amano, Centrifugal Compressor Performance Improvements Through Impeller Splitter Location, ASME Journal Energy Resource Technology 140 (2017), 0512010512016, doi: $10.1115 / 1.4037813$.

[12] C. Xu, R. S. Amano, Computational Analysis of Scroll Tongue Shape to Compressor Performance by Using Different Turbulence Models, International Journal for Computational Methods in Engineering Science and Mechanics, 11 (2010), 85-99.

[13] C. Xu, R. S. Amano, Computational Analysis of Swept Compressor Rotor Blades, International Journal for Computational Methods in Engineering Science and Mechanics, 9 (2008) 374-382.
[14] Fradin, C., Investigation of the Three Dimensional Flow near the Exit of Two Backswept Transonic Centrifugal Impellers, Proc. of the Eighth International Symposium in Air Breathing Engines, (1987) 149 -155.

[15] C. Xu, R. S. Amano, Centrifugal compressor design impacts: lean and meridional shape, GT2013-9411, (2013).

[16] C. Xu, R. S. Amano, On the Development of Turbine Blade Aerodynamic Design System, 2001-GT-0443 (2001).

[17] C. Xu, R. S. Amano, Meridional considerations of the centrifugal compressor development, International Journal of Rotating Machinery, (2012), 1-11, doi: 10.1155/2012/518381.

[18] C. Xu, R. S. Amano, Performance impacts of centrifugal compressor splitter location, GT2016-56017, (2014).

[19] C. Xu, R. S. Amano, Aerodynamic and structure considerations in centrifugal compressor design-blade lean effects, GT2012-68027 (2012).

[20] C. Xu, H. Q, Yang, Y. Zhongwei, The development of an integrally geared centrifugal compressor, International Journal of fluid mechanics and thermal sciences, vol 3, 2019. doi 10.11648/j.ijfmts.20190501.11.

[21] C. Xu, L. Chen, and RS Amano, Design System Development for a Fuel Cell Centrifugal Compressor, International Journal of fluid mechanics and thermal sciences, 2019; 5 (4): 96-101, doi: 10.11648/j.jifmts.20190504.12.

[22] F. J. Wiesner, A review of slip factors for centrifugal impellers, ASME J. of Eng for Power, 89 (1969), 558-572.

[23] Cheng Xu, Hanqian Yang, Yandan Jiang, Zhongwei Yi, The Development of an Integrally Geared Centrifugal Compressor, International Journal of Fluid Mechanics \& Thermal Sciences, Vol. 5, No. 1, 2019, pp. 1-9. doi: 10.11648/j.ijfmts.20190501.11.

[24] AK Steel, 17-4 PH stainless steel, AK steel Corp, West Chester, OH (2007).

[25] ASME, Performance Test Code on Compressors and Exhausters, PTC10-1997, 1997. 